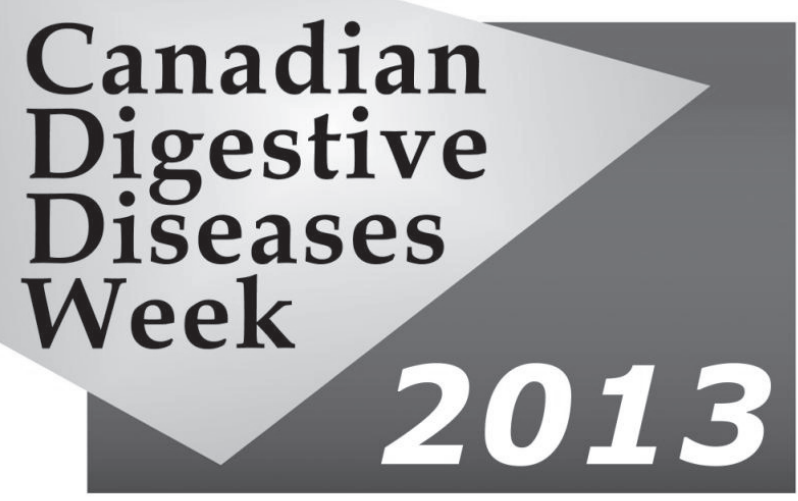

\title{
Thank you to the over 800 delegates who made CDDW 2013 a great success!
}

CDDW 2013 offered over 92 hours of Section 1 accredited learning and over 27 credits per delegate (over $1 / 4$ of your annual requirement!). Eighty-three sessions over a 3.5 day period included symposia, key lectures, breakfast sessions, small

group learning sessions, and paper sessions. Over 150 faculty members, including many international speakers, delivered the program.

\section{Help us improve the CDDW meeting to cover} the topics that are important to you and retrieve your MAINCert Certificate for CDDW!

Follow this link (http://www.cag-acg.org/) to the online CDDW evaluation. We appreciate your feedback and assistance with developing further CAG educational programs.

\section{Stay tuned to the CAG ePortal at http://www.cag-acg.org/cag-education-eportal}

If you missed CDDW 2013 or were unable to attend all of the sessions stay tuned to the CAG ePortal. We will be posting CDDW 2013 sessions over the coming months.

The CAG is proud to acknowledge its Benefactor Corporate Sponsors:

AbbVie Corporation

Pentax Canada Inc
Olympus Canada Inc

Janssen Inc

Takeda Canada Inc 


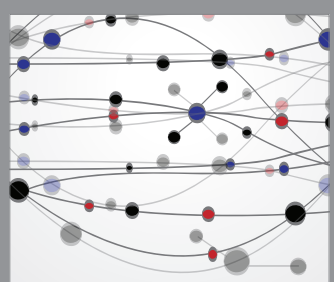

The Scientific World Journal
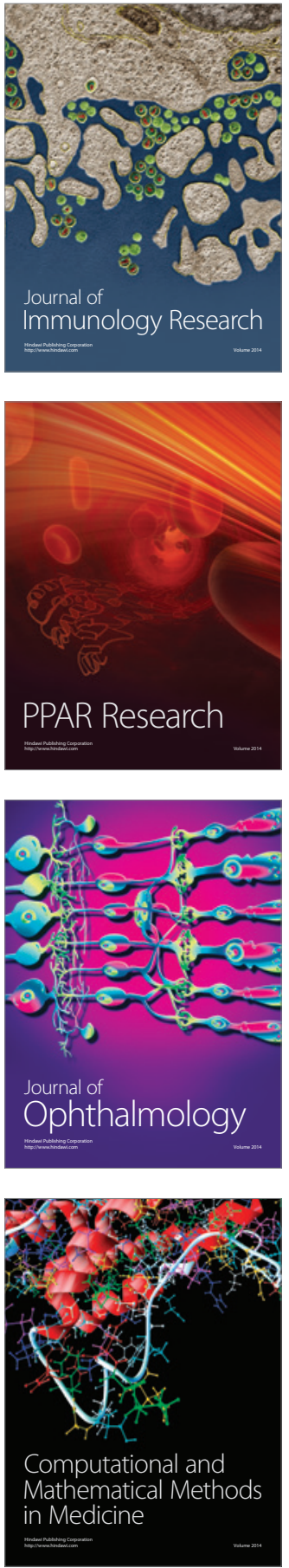

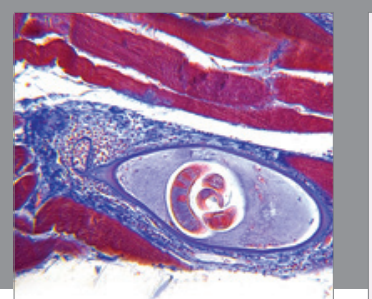

Gastroenterology Research and Practice

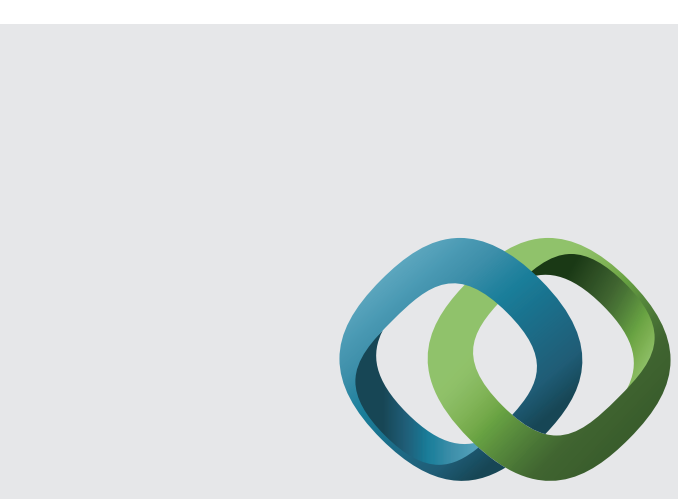

\section{Hindawi}

Submit your manuscripts at

http://www.hindawi.com
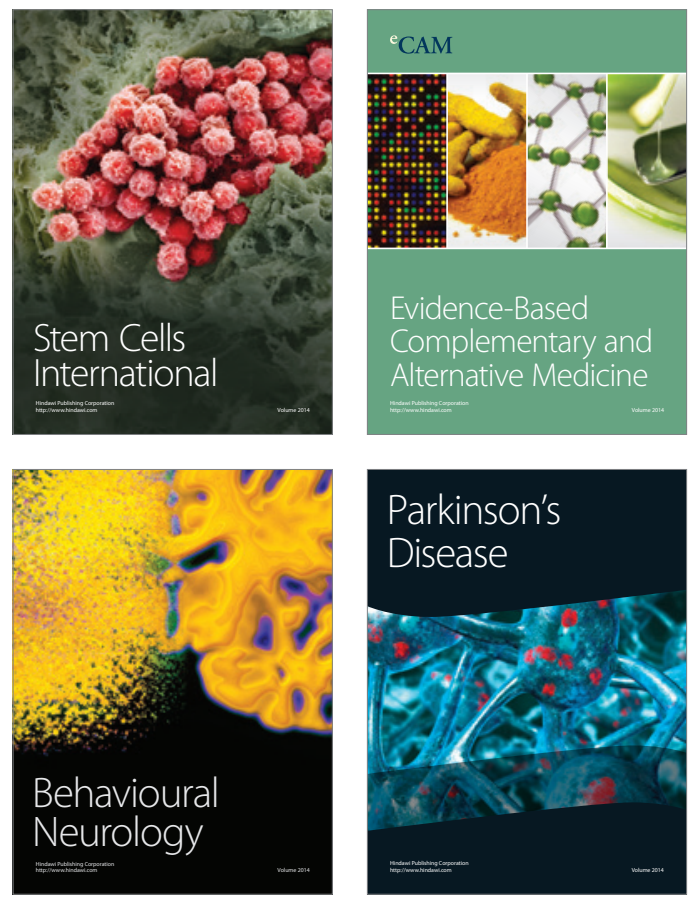
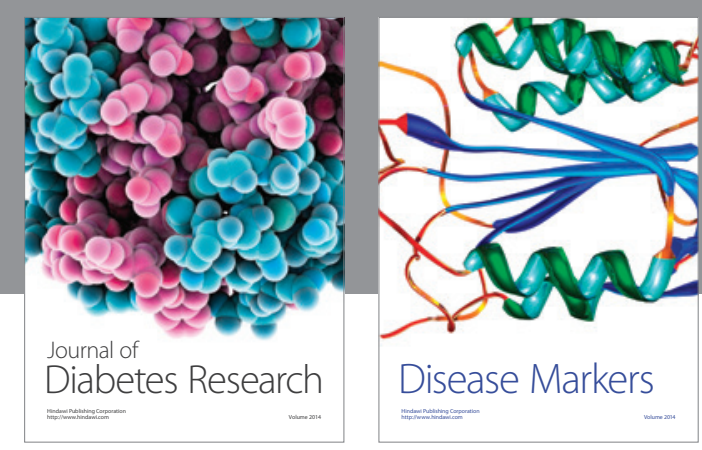

Disease Markers
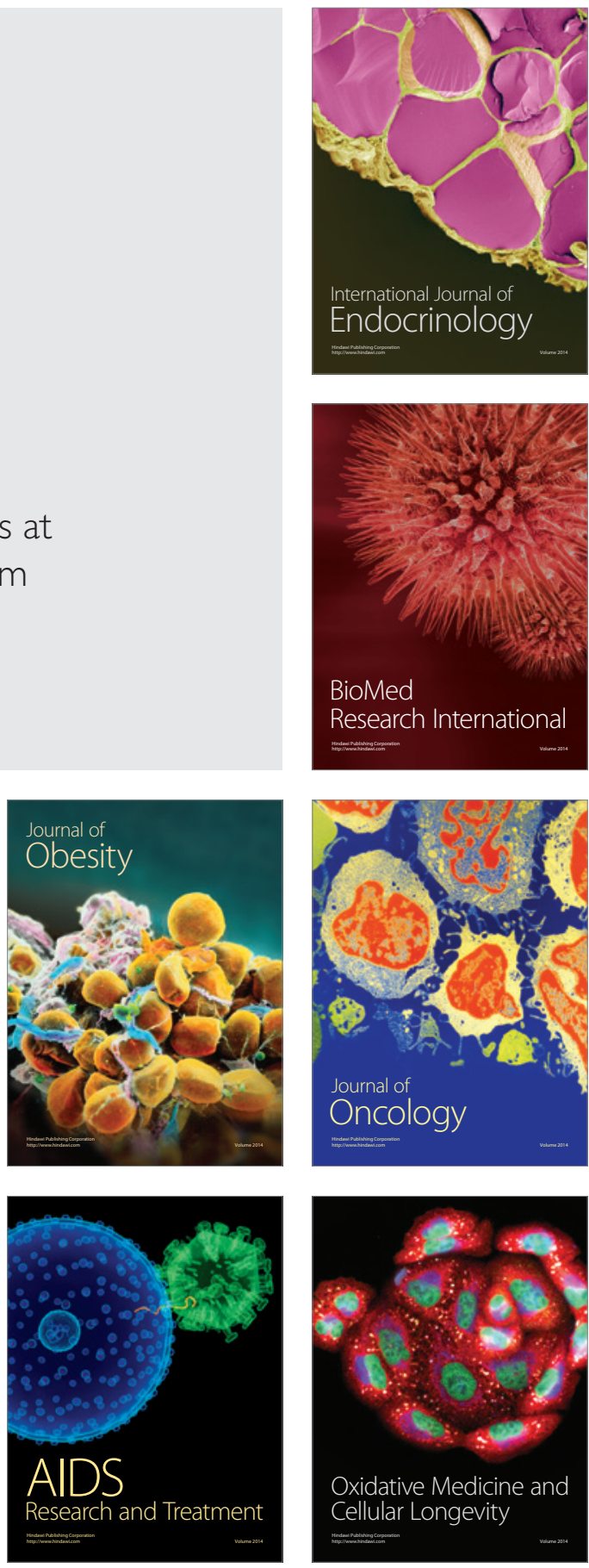